\title{
The Composition of Poly(Ethylene Terephthalate) (PET) Surface Precipitates Determined at High Resolving Power by Tandem Mass Spectrometry Imaging
}

Citation for published version (APA):

Fisher, G. L., Hammond, J. S., Bryan, S. R., Larson, P. E., \& Heeren, R. M. A. (2017). The Composition of Poly(Ethylene Terephthalate) (PET) Surface Precipitates Determined at High Resolving Power by Tandem Mass Spectrometry Imaging. Microscopy and Microanalysis, 23(4), 843-848.

https://doi.org/10.1017/S1431927617000654

Document status and date:

Published: 01/08/2017

DOI:

10.1017/S1431927617000654

Document Version:

Publisher's PDF, also known as Version of record

\section{Document license:}

Taverne

Please check the document version of this publication:

- A submitted manuscript is the version of the article upon submission and before peer-review. There can be important differences between the submitted version and the official published version of record. People interested in the research are advised to contact the author for the final version of the publication, or visit the DOI to the publisher's website.

- The final author version and the galley proof are versions of the publication after peer review.

- The final published version features the final layout of the paper including the volume, issue and page numbers.

Link to publication

\footnotetext{
General rights rights.

- You may freely distribute the URL identifying the publication in the public portal. please follow below link for the End User Agreement:

www.umlib.nl/taverne-license

Take down policy

If you believe that this document breaches copyright please contact us at:

repository@maastrichtuniversity.nl

providing details and we will investigate your claim.
}

Copyright and moral rights for the publications made accessible in the public portal are retained by the authors and/or other copyright owners and it is a condition of accessing publications that users recognise and abide by the legal requirements associated with these

- Users may download and print one copy of any publication from the public portal for the purpose of private study or research.

- You may not further distribute the material or use it for any profit-making activity or commercial gain

If the publication is distributed under the terms of Article 25fa of the Dutch Copyright Act, indicated by the "Taverne" license above, 


\title{
The Composition of Poly(Ethylene Terephthalate) (PET) Surface Precipitates Determined at High Resolving Power by Tandem Mass Spectrometry Imaging
}

\author{
Gregory L. Fisher, ${ }^{1, \star}$ John S. Hammond, ${ }^{1}$ Scott R. Bryan, ${ }^{1}$ Paul E. Larson, ${ }^{1}$ and Ron M. A. Heeren ${ }^{2}$ \\ ${ }^{1}$ Physical Electronics, Inc., Chanhassen, MN 55317, USA \\ ${ }^{2}$ Maastricht Multi-Modal Molecular Imaging (M4I) Institute, Maastricht University, 6211 ER Maastricht, The Netherlands
}

\begin{abstract}
We present the first demonstration of a general method for the chemical characterization of small surface features at high magnification via simultaneous collection of mass spectrometry (MS) imaging and tandem MS imaging data. High lateral resolution tandem secondary ion MS imaging is employed to determine the composition of surface features on poly(ethylene terephthalate) (PET) that precipitate during heat treatment. The surface features, probed at a lateral resolving power of $<200 \mathrm{~nm}$ using a surface-sensitive ion beam, are found to be comprised of ethylene terephthalate trimer at a greater abundance than is observed in the surrounding polymer matrix. This is the first chemical identification of PET surface precipitates made without either an extraction step or the use of a reference material. The new capability employed for this study achieves the highest practical lateral resolution ever reported for tandem MS imaging.
\end{abstract}

Key words: mass spectrometry imaging, tandem MS imaging, molecular identification, polymer surface analysis, TOF-SIMS

\section{INTRODUCTION}

There is a body of published work spanning some 34 years concerning the identification of precipitates formed at the surface of thermally treated poly(ethylene terephthalate) (PET) (Perovik \& Sundararajan, 1982; Briggs, 1986; Reichlmeier et al., 1995). This collection of work leads the reader to infer that the surface precipitates are comprised of crystalline ethylene terephthalate trimer. In this article we demonstrate that, with a single high spatial resolution analysis simultaneously collecting both mass spectrometry $\left(\mathrm{MS}^{1}\right)$ imaging data and tandem mass spectrometry $\left(\mathrm{MS}^{2}\right)$ imaging data, one can directly deduce the chemical composition of the surface precipitates on heat-treated PET. This new method of molecular imaging and identification is broadly applicable in fields of medicine and pathology, performance materials, forensics, food science, pharmaceuticals, geology, electronic materials, power storage, and failure analysis. We establish, in the present study, a rapid method of molecular imaging and identification for use in such fields of investigation.

The treatment or modification of polymers has been of interest for many decades. The selected alterations serve to vary the friction and wear characteristics, chemical resistance, strength, hardness, and toughness of the affected polymer. Polymers used in various applications are commonly subject to thermal cycling which may induce additive blooming as well as changes in tacticity, morphology, and phase composition. PET is one of the most widely used polymers for food packaging

Received April 14, 2017; accepted May 11, 2017

*Corresponding author. gfisher@phi.com owing to global health safety approval and sustainability (Yates, 2000; Achilias \& Karayannidis, 2004). PET is also one of the most common polymers used in the textile industry (Perovik \& Sundararajan, 1982; Wolf, 2010). The outcome of modifications to a textile or food packaging polymer are of concern because of the relationship between the surface properties and, e.g., permeability, dyeability or printability, adhesion, and metallization (Parvinzadeh Gashti et al., 2011; Rudolf et al., 2012).

The first comprehensive reporting of thermally induced precipitates on the surface of PET was made by Perovik and Sundararajan in 1982 with the usesecondary electron microscope (SEM) imaging. Their chemical characterization involved a solvent extraction of a film specimen followed by nuclear magnetic resonance analysis of the evaporation residue. They reported that the features observed by SEM were comprised of cyclic ethylene terephthalate trimer. However, a vulnerability of a solvent extraction is that differences in surface and bulk chemistry will be lost. The first reported use of a surface-sensitive analytical technique to characterize heattreated PET films made use of secondary ion mass spectrometry (SIMS) (Briggs, 1986). A purified specimen of pressed cyclic ethylene terephthalate trimer was used to collect a reference spectrum for comparison with the spectra of heattreated PET films. The purified specimen produced a prominent peak at $m / z 577$ in the positive ion polarity, ostensibly the protonated ethylene terephthalate trimer ion. The same $\mathrm{m} / \mathrm{z}$ 577 peak was observed in spectra of the heat-treated PET films, albeit at lower integrated intensity. A decade later, Reichlmaier et al. in 1995 interrogated various heat-treated films of PET with time-of-flight SIMS (TOF-SIMS) imaging and observed that an $\mathrm{m} / \mathrm{z} 577$ feature in the positive ion polarity was 
localized to small domains on the surface. This early MS imaging analysis did not have the benefit of direct molecular identification, so the composition of the peak at $\mathrm{m} / z 577$ was again reasoned, based on the work of Briggs, to be the protonated ethylene terephthalate trimer.

In this work, we have deployed a new method of tandem MS imaging for molecular identification at high resolving power. We demonstrate high lateral resolution imaging of the thermally induced surface precipitates concurrent with identification of the $m / z 577$ peak as ethylene terephthalate trimer. We observe that the ethylene terephthalate trimer signal emanates predominantly from the surface precipitates and that sodium, which evolves from the bulk to the surface during heat treatment, is situated outside the ethylene terephthalate precipitates.

\section{Materials and Methods}

Films of PET manufactured from terephthalic acid (ICI plc, Middlesborough, England) were utilized for heat treatment. Samples measuring $\sim 3 \mathrm{~cm} \times 3 \mathrm{~cm} \times 300 \mu \mathrm{m}$-thick were placed on a hot plate in a laboratory ambient atmosphere at $170-200^{\circ} \mathrm{C}$ for $\sim 2 \mathrm{~h}$ as described by Reichlmeier et al. in 1995. The samples were introduced to vacuum for analysis $\sim 1$ week following heat treatment. The TOF-SIMS parallel imaging MS/MS analysis was performed using the TOF-TOF tandem MS on a PHI nanoTOF II instrument (Physical Electronics, Chanhassen, MN, USA) equipped with a $30 \mathrm{kV}$ liquid metal ion gun (Larson et al., 2015; Fisher et al., 2016a, 2016b). The samples were interrogated by a mass pure $\mathrm{Bi}_{n}^{q+}$ cluster ion beam having a dc current of $6 \mathrm{nA}$. Each 32 ns pulse of the $\mathrm{Bi}_{3}^{+}$primary ion beam was digitally rasterscanned across $256 \times 256$ pixels of the $40 \times 40 \mu$ m analytical fieldof-view (FOV). The primary ion dose density of $4.82 \times 10^{12} \mathrm{Bi}_{3}^{+} /$ $\mathrm{cm}^{2}$ that was used to generate the MS imaging data was below the static limit, and the total analysis time was $13 \mathrm{~min}$. The MS ${ }^{1}$ and $\mathrm{MS}^{2}$ data were collected simultaneously and synchronously for each primary ion pulse delivered to the digitally rasterscanned image pixels, i.e., one primary ion pulse triggers one parallel cycle of the $\mathrm{MS}^{1}$ and $\mathrm{MS}^{2}$. The images and spectra reported here were produced retrospectively from the raw data file using PHI SmartSoft-TOF and PHI TOF-DR software (Physical Electronics).

The TOF-TOF imaging MS used for this analysis is tandem in time. That is to say, there are two TOF spectrometers that operate in parallel. The TOF spectrometers are triggered together at a typical frequency of $8,300 \mathrm{~Hz}$ when the primary ion pulses are delivered to the sample. The MS ${ }^{1}$ data arises from the TRiple Ion Focusing Time-of-flight (TRIFT) spectrometer, and the $\mathrm{MS}^{2}$ data arises the linear TOF spectrometer. The $\mathrm{MS}^{2}$ duty cycle is $52 \mu$ s and is completed within the $120 \mu$ s duty cycle of the MS ${ }^{1}$. Hence, the $\mathrm{MS}^{1}$ and $\mathrm{MS}^{2}$ data are collected synchronously and from precisely the same analytical volume interrogated by the primary ion beam. There is a focus of the secondary ions at the location of the precursor selector which is a product of the TRIFT's original imaging ion microscope design (Schueler, 1992). At this focal point in the TRIFT spectrometer, the secondary ions have reached almost complete
TOF separation. Monoisotopic (i.e., $1 \mathrm{Da}$ ) precursor selection is realized as a consequence of both the TOF mass separation and the spatial focusing.

\section{Results And Discussion}

TOF-SIMS parallel imaging MS/MS analysis of heat-treated PET specimens was performed in the positive ion polarity, with a monoisotopic precursor selection window centered at $m / z 577.13$, to both observe the lateral distribution and to identify without ambiguity the composition of the surface precipitates. The high selectivity of the precursor ions has been demonstrated and recently reported (Fisher et al., 2016b). The design and operating characteristics of the TOF-SIMS parallel imaging MS/MS instrument is described fully elsewhere, including schematic diagrams that provide a conceptual understanding of the instrument construct and function (Fisher et al., 2016a, 2016b). The $1 \mathrm{Da}$ precursor selection is smaller than the 4-10 Da window commonly used in other tandem MS designs. Therefore, interpretation of the resulting product ion spectrum is simplified and does not require extraordinary performance in mass resolution or mass accuracy (Satoh et al., 2011; Shimma et al., 2012). What is more, high-energy (i.e., $\mathrm{keV}$ ) collision-induced dissociation (CID) provides an advantage over low-energy CID because it enables structural elucidation in addition to compositional identification.

The monoisotopic window of precursor ions in the TRIFT $\left(\mathrm{MS}^{1}\right)$ spectrometer are deflected at $\approx 1.5 \mathrm{keV}$ into the activation cell of the linear TOF $\left(\mathrm{MS}^{2}\right)$ spectrometer while the remainder travel on to the $\mathrm{MS}^{1}$ detector. Following fragmentation in the activation cell, the product ions and unfragmented precursor ions are bunched, postaccelerated, and travel on to the $\mathrm{MS}^{2}$ detector. No $\mathrm{MS}^{1}$ data are discarded in the acquisition of $\mathrm{MS}^{2}$ data. This point is illustrated in

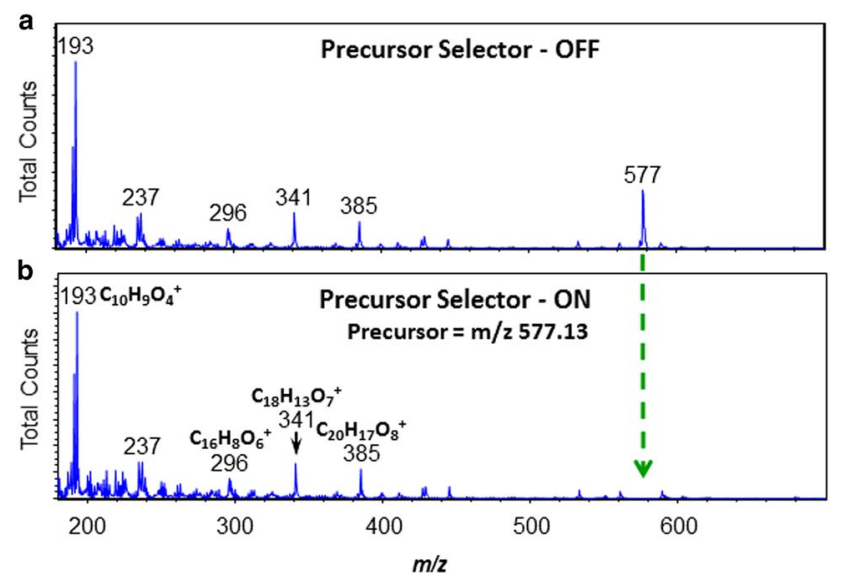

Figure 1. a: Mass spectrometry $\left(\mathrm{MS}^{1}\right)$ positive polarity precursor ion spectrum in the range of $m / z 180-700$. The precursor selector is de-energized. $\mathbf{b}$ : $\mathrm{MS}^{1}$ positive polarity precursor ion spectrum in the range of $m / z 180-700$. The precursor selector, with a monoisotopic (i.e., $1 \mathrm{Da}$ ) window centered at $\mathrm{m} / z 577.13$, is energized at $100 \%$ duty cycle such that it is pulsed at the same frequency as that of the analytical primary ion beam. The peaks are labeled based on the tandem MS identification as discussed in the text. 
Figure 1 where the $\mathrm{MS}^{1}$ spectra are displayed with and without precursor ion deflection into the activation cell. The percent duty cycle of the precursor selection is variable by the operator such that, if desired, a fractional portion of the precursor ions may be selected to remain in the $\mathrm{MS}^{1}$ spectrum for the purposes of normalization or quantification. The preservation of $\mathrm{MS}^{1}$ data provides an internal calibration of the $\mathrm{MS}^{2}$ data and the need for an exogenous calibration reference is eliminated.

The $\mathrm{MS}^{2}$ product ion spectrum of the $\mathrm{m} / z 577$ precursor is provided in Figure 2 wherein the diagnostic product ions are labeled. In order of ascending mass-to-charge ratio, they are $\mathrm{C}_{7} \mathrm{H}_{4} \mathrm{O}^{+}(m / z 104), \mathrm{C}_{8} \mathrm{H}_{5} \mathrm{O}_{3}^{+}(m / z 149), \mathrm{C}_{10} \mathrm{H}_{9} \mathrm{O}_{4}^{+}\left([\mathrm{M}+\mathrm{H}]^{+}\right.$, $m / z$ 193), $\mathrm{C}_{17} \mathrm{H}_{13} \mathrm{O}_{5}^{+}(m / z \quad 297), \mathrm{C}_{18} \mathrm{H}_{13} \mathrm{O}_{7}^{+} \quad(m / z \quad 341)$, $\mathrm{C}_{20} \mathrm{H}_{17} \mathrm{O}_{8}^{+}\left([2 \mathrm{M}+\mathrm{H}]^{+}, m / z 385\right), \mathrm{C}_{28} \mathrm{H}_{21} \mathrm{O}_{11}^{+}(m / z 533)$, and $\mathrm{C}_{30} \mathrm{H}_{25} \mathrm{O}_{12}^{+}\left([3 \mathrm{M}+\mathrm{H}]^{+}, m / z 577\right)$. The product ion spectrum provides conclusive evidence that the $m / z 577$ precursor is the protonated quasi-molecular ion of ethylene terephthalate trimer, $[3 \mathrm{M}+\mathrm{H}]^{+}$. The $\mathrm{MS}^{2}$ mass resolution $(m / \Delta m)$ is measured at full-width and half-maximum to be 1,652 at $\mathrm{m} / z$ $193\left([\mathrm{M}+\mathrm{H}]^{+}\right), 1,830$ at $m / z 385\left([2 \mathrm{M}+\mathrm{H}]^{+}\right)$, and 2,240 at $m / z$ $577\left([3 \mathrm{M}+\mathrm{H}]^{+}\right)$. The mass deviation across all calibration peaks of the product ion spectrum is $4.67 \mathrm{mDa}$ root mean square, and the mass accuracy at the precursor is $3.35 \mathrm{ppm}$. The $\mathrm{MS}^{2}$ product ion spectrum provides an accompanying benefit in that it may be used for the identification of peaks observed in the $\mathrm{MS}^{1}$ spectrum since they appear at the same mass-to-charge ratios.

The $\mathrm{MS}^{1}$ images are shown in the top row of Figure 3 and the MS ${ }^{2}$ images are shown in the bottom row of Figure 3. The images were collected wherein a primary ion pulse generates both $\mathrm{MS}^{1}$ and $\mathrm{MS}^{2}$ spectra at each digitally

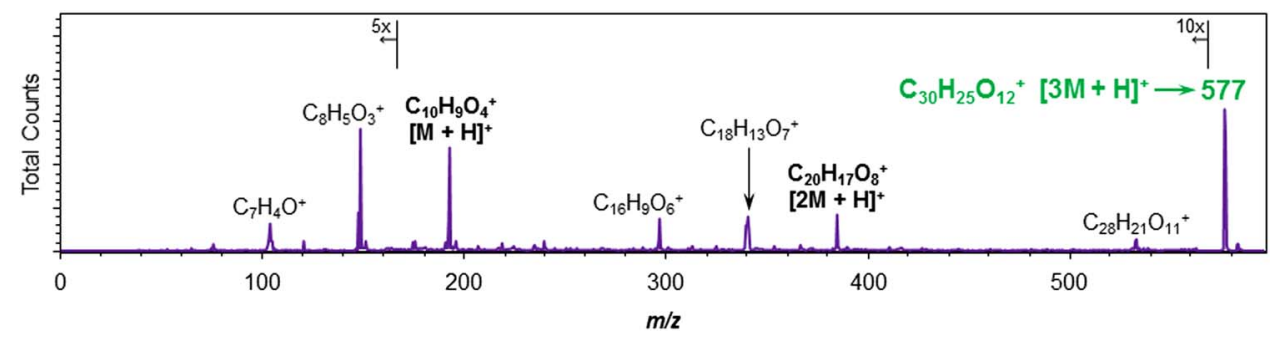

Figure 2. The positive ion polarity CID product ion tandem mass spectrometry $\left(\mathrm{MS}^{2}\right)$ spectrum of the $\mathrm{m} / z 577$ precursor arising from a heat-treated film of poly(ethylene terephthalate). The $\mathrm{MS}^{2}$ spectrum represents a sum of all image pixels. Each of the diagnostic peaks are labeled.

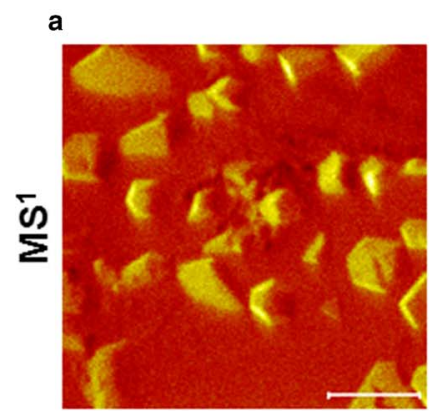

TIC

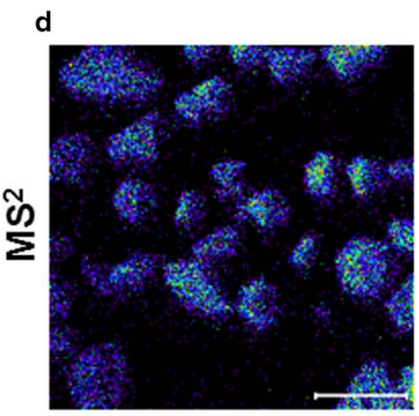

TIC

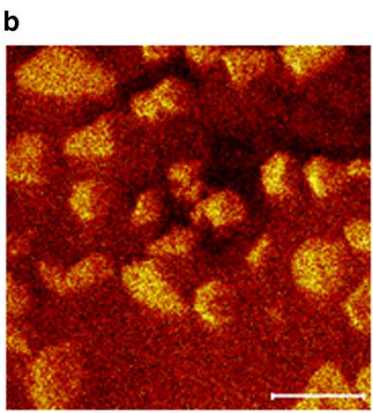

$\mathrm{C}_{8} \mathrm{H}_{5} \mathrm{O}_{3}{ }^{+}(m / z$ 149)

e

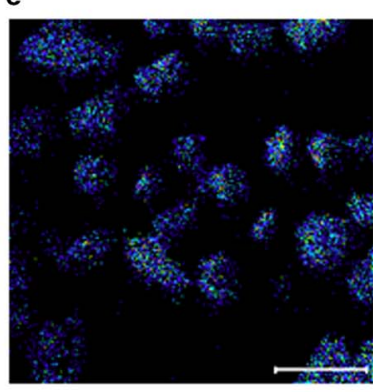

$\mathrm{C}_{8} \mathrm{H}_{5} \mathrm{O}_{3}{ }^{+}(\mathrm{m} / \mathrm{z} 149)$

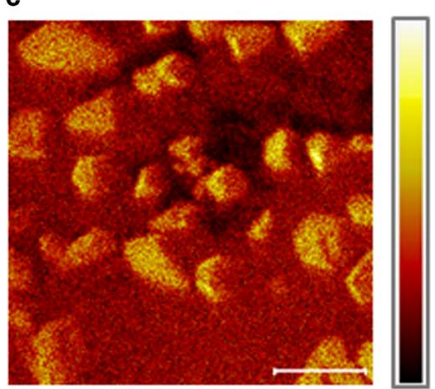

$\mathrm{C}_{7} \mathrm{H}_{4} \mathrm{O}^{+}(\mathrm{m} / \mathrm{z}$ 104)

f

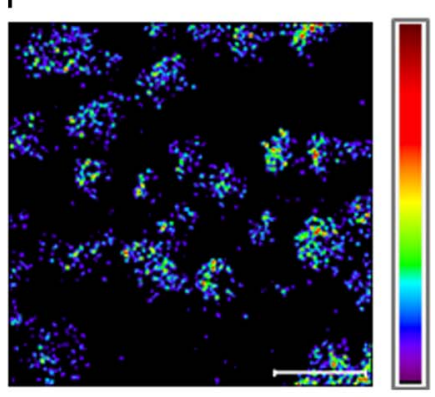

$\mathrm{C}_{7} \mathrm{H}_{4} \mathrm{O}^{+}(\mathrm{m} / \mathrm{z}$ 104)

Figure 3. a-c: Mass spectrometry $\left(\mathrm{MS}^{1}\right)$ total ion and ion-specific images. $\mathbf{d}-\mathbf{f}$ : Tandem mass spectrometry $\left(\mathrm{MS}^{2}\right)$ total ion and product ion images arising from fragmentation of the $\mathrm{m} / z 577$ precursor. The $\mathrm{MS}^{1}$ and $\mathrm{MS}^{2}$ images reveal that the $[3 \mathrm{M}+\mathrm{H}]^{+}$precursor $(\mathrm{m} / z 577)$ and the corresponding CID product ions emanate predominantly from the surface precipitates. The images are $40 \times 40 \mu \mathrm{m}$; the scale markers are $10 \mu \mathrm{m}$. All images are displayed on a linear scale. TIC, total ion current. 
raster-scanned image pixel. Thus, in a single measurement, the information content from the specified analytical volume is maximized. The primary ion beam was operated in the unbunched mode (i.e., no electrodynamic time compression) during analysis to achieve the best lateral resolution; therefore, only unit mass resolution is realized in the $\mathrm{MS}^{1}$ spectrum. The mass resolution of the $\mathrm{MS}^{1}$ spectrum is defined by the time duration of the primary ion pulse(s) (Cotter, 1997). However, the mass resolution of $\mathrm{MS}^{2}$ is decoupled from that of $\mathrm{MS}^{1}$ because the $\mathrm{MS}^{2}$ contains electrodynamic time compression and postacceleration optics following the CID cell. The mass resolving power in both $\mathrm{MS}^{1}$ and $\mathrm{MS}^{2}$ as a function of time compression of the primary ion beam has been discussed and illustrated by Fisher et al. (2016b). Without electrodynamic time compression, the 32 ns primary ion pulses produce flat-top "unit resolution" peaks at each nominal mass of the $\mathrm{MS}^{1}$ spectrum. However, full mass resolution is attained in the $\mathrm{MS}^{2}$ spectrum, independent of the mass resolution in the $\mathrm{MS}^{1}$ spectrum, whereas high lateral resolution is achieved in both the $\mathrm{MS}^{1}$ and the $\mathrm{MS}^{2}$ images. This utilitarian feature allows unprecedented molecular identification at $<200 \mathrm{~nm}$ feature resolution. By operating the TOF-TOF spectrometer in the product ion scan mode, one concurrently achieves separation of the matrix components by $\mathrm{MS}^{1}$ imaging and targeted identification of matrix components by $\mathrm{MS}^{2}$ imaging. If an isobaric interference happens to exist within the $1 \mathrm{Da}$ precursor selection window, the interfering species are easily observed and identified in the product ion spectrum.

Taken together, the $\mathrm{MS}^{1}$ and $\mathrm{MS}^{2}$ images of Figure 3 reveal that the ethylene terephthalate trimer $[3 \mathrm{M}+\mathrm{H}]^{+}$ions at $\mathrm{m} / \mathrm{z} 577$ arise predominantly from the thermally precipitated surface features. Fragment ions of PET, such as $\mathrm{C}_{8} \mathrm{H}_{5} \mathrm{O}_{3}^{+}\left(m / z\right.$ 149) and $\mathrm{C}_{7} \mathrm{H}_{4} \mathrm{O}^{+}(\mathrm{m} / z$ 104), are observed in $\mathrm{MS}^{1}$ to emanate from both the surface precipitates and the surrounding polymer. The $\mathrm{C}_{8} \mathrm{H}_{5} \mathrm{O}_{3}^{+}$and $\mathrm{C}_{7} \mathrm{H}_{4} \mathrm{O}^{+}$ions originating near the center of the $\mathrm{FOV}$ in $\mathrm{MS}^{1}$ appear to be suppressed. The presence of alkali metals in high abundance is a known cause of molecular ion suppression (Piwowar et al., 2009). The $\mathrm{MS}^{1}$ images reveal that $\mathrm{Na}^{+}\left(\mathrm{m} / z\right.$ 23) and $\mathrm{K}^{+}$ $(\mathrm{m} / z$ 39) are co-localized with the dark regions observed in the $\mathrm{C}_{8} \mathrm{H}_{5} \mathrm{O}_{3}^{+}$and $\mathrm{C}_{7} \mathrm{H}_{4} \mathrm{O}^{+}$images, and so the presence of the alkali metals explains the depressed signal from the polymer matrix. This co-localization is demonstrated for $\mathrm{Na}^{+}$in the overlay image presented in Figure 4. In addition, the $\mathrm{MS}^{1}$ ion yields are observed to be greater in the surface precipitates than in the surrounding polymer matrix. An increase in the molecular density, as would be the case for crystalline phases, most often produces an increase of the overall ion yield (Winograd \& Garrison, 1991). We can therefore infer that the surface precipitates have a greater molecular density than the surrounding polymer.

In $\mathrm{MS}^{2}$, the $\mathrm{C}_{8} \mathrm{H}_{5} \mathrm{O}_{3}^{+}$and $\mathrm{C}_{7} \mathrm{H}_{4} \mathrm{O}^{+}$ions are products of neutral loss from the $[3 \mathrm{M}+\mathrm{H}]^{+}$precursor ions. As the $[3 \mathrm{M}+\mathrm{H}]^{+}$precursor is highly localized to the surface crystals, the $\mathrm{C}_{8} \mathrm{H}_{5} \mathrm{O}_{3}^{+}$and $\mathrm{C}_{7} \mathrm{H}_{4} \mathrm{O}^{+}$products are also observed to be localized to the surface crystals. In addition, the $\mathrm{MS}^{1}$ and $\mathrm{MS}^{2}$ images may be used together to evaluate the lateral
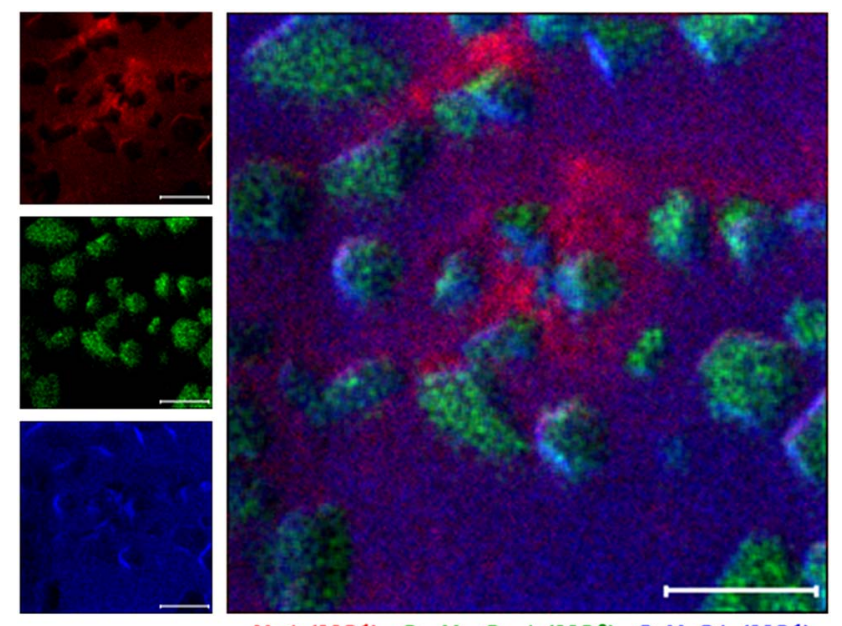

$\mathrm{Na}^{+}\left(\mathrm{MS}^{1}\right), \mathrm{C}_{30} \mathrm{H}_{25} \mathrm{O}_{12}{ }^{+}\left(\mathrm{MS}^{2}\right), \mathrm{C}_{4} \mathrm{H}_{7} \mathrm{O}^{+}\left(\mathrm{MS}^{1}\right)$

Figure 4. False color overlay image (at right) of $\mathrm{Na}^{+}$(red), $[3 \mathrm{M}+\mathrm{H}]^{+}$(green), and $\mathrm{C}_{3} \mathrm{H}_{7} \mathrm{O}^{+}$(blue). The individual ion images are shown at left. The mass spectrometry $\left(\mathrm{MS}^{1}\right)$ and tandem mass spectrometry $\left(\mathrm{MS}^{2}\right)$ data were collected simultaneously from the same analytical volume. The images are $40 \times 40 \mu \mathrm{m}$; the scale marker is $10 \mu \mathrm{m}$.

distribution of chemistry. The overlay image disclosed in Figure 4 reveals a high abundance of $\mathrm{Na}^{+}$in areas of the sample with low organic ion signals as mentioned and discussed in the previous paragraph. This phenomenon was mentioned briefly by Reichlmeier et al. (1995) who observed a trend of increased $\mathrm{Na}^{+}$abundance at the surface with increased duration of the thermal treatment. Owing to the greater spatial resolution of the present analysis, we can establish that the surface segregation of sodium occurs around the precipitates and not within the precipitates. Moreover, we can substantiate that the abundance of ethylene terephthalate trimer is much greater in the surface precipitates than in the surrounding polymer matrix. We have calculated this difference using the ethylene terephthalate trimer signal $\left([3 \mathrm{M}+\mathrm{H}]^{+}, m / z 577\right)$ normalized to a polymer fragment $\left(\mathrm{C}_{7} \mathrm{H}_{4} \mathrm{O}^{+}, m / z\right.$ 104), and we arrive at a value of 6.1 which agrees well with expectations based on the data produced by Briggs (1986).

In Figure 5, we reveal the measured lateral resolution $(\Delta l)$ determined from a curve fit to a line scan of 4 pixel averaging width and using 80 and $20 \%$ bounds. The results of multiple line scans reveal $\mathrm{MS}^{1}$ and $\mathrm{MS}^{2}$ imaging at $<200 \mathrm{~nm}$ lateral resolution. As an example, the line scan on the $\mathrm{MS}^{1}$ image of $\mathrm{C}_{7} \mathrm{H}_{4} \mathrm{O}^{+}$reveals a resolution of $172 \mathrm{~nm}$. Likewise, a line scan on the $\mathrm{MS}^{2}$ image of $[3 \mathrm{M}+\mathrm{H}]^{+}$exhibits a resolution of $148 \mathrm{~nm}$.

\section{CONCLUSION}

The new tandem MS imaging spectrometer provides enormous power to the surface characterization method of TOF-SIMS for discovery and failure analysis in fields of high-performance materials, polymers, biology, pathology, 

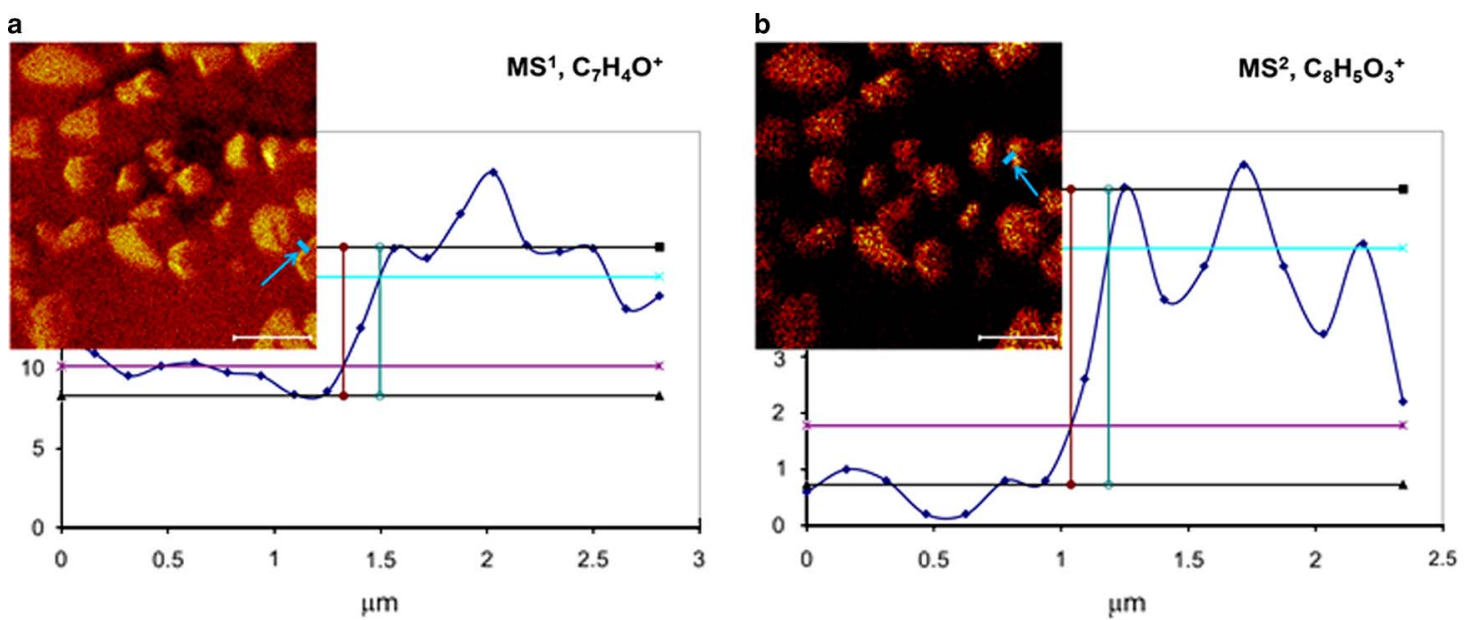

Figure 5. a: Line scan measurement on the mass spectrometry $\left(\mathrm{MS}^{1}\right)$ image of $\mathrm{C}_{7} \mathrm{H}_{4} \mathrm{O}^{+}(\mathrm{m} / z$ 104). The measured lateral resolution $(\Delta l)$ is $172 \mathrm{~nm}$. b: Line scan measurement on the tandem mass spectrometry $\left(\mathrm{MS}^{2}\right)$ image of $[3 \mathrm{M}+\mathrm{H}]^{+}(m / z 577)$. The measured lateral resolution $(\Delta l)$ is $148 \mathrm{~nm}$. In each case, an averaging of 4 pixels was used in the line scan. The images are $40 \times 40 \mu \mathrm{m}$.

pharmaceuticals, food sciences, power generation and storage devices, and forensics, to name just a few disciplines. The high speed of the TOF-TOF spectrometer allows concurrent surface screening of matrix components by $\mathrm{MS}^{1}$ imaging and targeted identification of matrix components by $\mathrm{MS}^{2}$ imaging in just a few minutes. The pulse counting detectors of the $\mathrm{MS}^{1}$ and the $\mathrm{MS}^{2}$ provide great sensitivity for $\mathrm{MS}^{1}$ and $\mathrm{MS}^{2}$ imaging. Therefore, numerous tandem MS imaging analyses can be performed on a typical sample, which is an advantage for maximizing the useful data obtained from "precious" or one-of-a-kind samples. For the characterization of molecular moieties, the combination of monoisotopic precursor selection and kiloelectronvolt collisional activation literally propels the TOF-SIMS analyst from making an educated guess at molecular identification to achieving unequivocal molecular identification. In essence, molecular identification by the TOF-SIMS analyst has progressed from "I think" to "I know".

We have employed TOF-SIMS parallel imaging MS/MS for unambiguous molecular identification of surface precipitates on heat-treated PET. The highest resolving power ever reported for tandem MS imaging has been demonstrated. High mass resolution is realized in $\mathrm{MS}^{2}$, whereas a practical lateral resolution of $<200 \mathrm{~nm}$ is simultaneously achieved in both $\mathrm{MS}^{1}$ and $\mathrm{MS}^{2}$ imaging. Further, no $\mathrm{MS}^{1}$ data are discarded in the execution of an $\mathrm{MS}^{2}$ analysis. Hence, without the need for sample extractions, reference materials or applied calibration moieties, and in a single analysis on the order of $10 \mathrm{~min}$, we have proven that the surface precipitates on heattreated PET are comprised of ethylene terephthalate trimer.

\section{ACKNOWLEDGMENTS}

The authors thank Dr. Stefan Reichlmeier, PHI GmbH, for his aid in preparing the heat-treated PET films. R.M.A.H. acknowledges project/research support from the Dutch Province of Limburg.

\section{REFERENCES}

Achilias, D.S. \& Karayannidis, G.P. (2004). The chemical recycling of PET in the framework of sustainable development. Water Air Soil Pollut 4, 385-396.

BRIGGS, D. (1986). Analysis of polymer surfaces by SIMS, Part 6: Detection of cyclic oligomer on the surface of poly(ethylene terephthalate) film. Surf Int Anal 8, 133-136.

CotTer, R.J. (1997). SIMS instruments. In Time-of-Flight Mass Spectrometry: Instrumentation and Applications in Biological Research, Cotter, R.J. (Ed.), pp. 99-111. Washington, DC: ACS.

Fisher, G.L., Bruinen, A.L., Ogrinc Potočnik, N., Hammond, J.S., Bryan, S.R., Larson, P.E. \& HeEren, R.M.A. (2016a). A new method and mass spectrometer design for TOF-SIMS parallel imaging MS/MS. Anal Chem 88, 6433-6440.

Fisher, G.L., Hammond, J.S., Larson, P.E., Bryan, S.R. \& Heeren, R.M.A. (2016b). Parallel imaging MS/MS TOF-SIMS instrument. In SIMS XX Proceedings, Castner, D. (Ed.), NJ: Wiley, https://doi.org/10.1116/1.4943568.

Larson, P.E., Hammond, J.S., Heeren, R.M.A. \& Fisher, G.L. (2015). Method and apparatus to provide parallel acquisition of MS/MS data. U.S. Patent 20150090874.

Parvinzadeh Gashti, M., Willoughby, J. \& Agrawal, P. (2011). Surface and bulk modification of synthetic textiles to improve dyeability. In Textile Dyeing, Hauser, P. (Ed.), pp. 261-298. Rijeka: InTech Europe.

Perovik, A. \& Sundararajan, P.R. (1982). Crystallization of cyclic oligomers in commercial poly(ethylene terephthalate) films. Polym Bull 6, 277-283.

Piwowar, A.M., LOCKyer, N.P. \& Vickerman, J.C. (2009). Salt effects on ion formation in desorption mass spectrometry: An investigation into the role of alkali chlorides on peak suppression in time-of-flight secondary ion mass spectrometry. Anal Chem 81, 1040-1048.

Reichlmeier, S., Bryan, S.R. \& Briggs, D. (1995). Surface trimer crystallization on poly(ethylene terephthalate) studied by timeof-flight secondary ion mass spectrometry. J Vac Sci Technol A13, 1217-1223.

Rudolf, A., GerŠAK, J. \& SMOLE, M.S. (2012). The effect of heat treatment conditions using the drawing process on the properties of PET filament sewing thread. Text Res J 82, 161-171. 
Satoh, T., Sato, T., Kubo, A. \& Tamura, J. (2011). Tandem time-offlight mass spectrometer with high precursor ion selectivity employing spiral ion trajectory and improved offset parabolic reflectron. J Am Soc Mass Spectrom 22, 797-803.

Schueler, B.W. (1992). Microscope imaging by time-of-flight secondary ion mass spectrometry. Microsc Microanal Microstruct 3, 119-139.

Shimma, S., Kubo, A., Satoh, T. \& Toyoda, M. (2012). Detailed structural analysis of lipids directly on tissue specimens using a MALDI-SpiralTOF-Reflectron TOF mass spectrometer. PLoS ONE 7, e37107.
Winograd, N. \& Garrison, B.J. (1991). Surface structure and reaction studies by ion-solid collisions. In Ion Spectroscopies for Surface Analysis, Czanderna, A.W. \& Hercules, D.M. (Eds.), pp. 45-135. New York: Plenum.

Wolf, R.A. (2010). Primary polymer adhesion issues with inks, coatings, and adhesives. In Plastic Surface Modification: Surface Treatment and Adhesion, Wolf, R.A. (Ed.), pp. 3-12 and 81-155. Munich: Hanser-Verlag GmbH.

YATES, K. (2000). Report on packaging materials: 1. Polyethylene terephthalate (PET) for food packaging applications. ILSI Europe, Brussels. 